\title{
Nutritional status of the Andean population of Puna and Quebrada of Humahuaca, Jujuy, Argentina
}

\author{
D Romaguera ${ }^{1}, \mathrm{~N} \mathrm{Samman}{ }^{2}, \mathrm{~N}$ Farfán ${ }^{2}, \mathrm{M} \mathrm{Lobo}^{2}, \mathrm{~A} \mathrm{Pons}^{1}$ and JA Tur ${ }^{1, *}$ \\ ${ }^{1}$ Research Group on Community Nutrition and Oxidative Stress, Research Institute of Health Sciences, University \\ of the Balearic Islands, Guillem Colom Bldg, Campus, E-07122 Palma de Mallorca, Spain: ${ }^{2}$ Research Center of \\ Food Technology, Faculty of Engineering, National University of Jujuy, 4600 San Salvador de Jujuy, Argentina
}

Submitted 16 November 2006: Accepted 12 July 2007: First published online 26 September 2007

\begin{abstract}
Objective: To assess the nutritional status of the Andean population of Puna and Quebrada of Humahuaca, Jujuy, using anthropometric measurements.

Design and subjects: A cross-sectional nutritional survey was carried out in a representative sample $(n=1236)$ of individuals from these regions. Children aged $2-9$ years, adolescents (10-17 years) and adults ( $\geq 18$ years; pregnant and lactating women excluded) were considered. Height-for-age, weight-for-height and body mass index (BMI) were calculated in children and adolescents and compared with World Health Organization/National Center for Health Statistics/ Centers for Disease Control and Prevention reference standards using Z-scores or percentiles, in order to assess the prevalence of stunting, wasting/thinness and excess weight. In adults, BMI, waist circumference (WC) and waist-to-hip (WHR) ratio were used to identify obesity and central adiposity.

Results: Stunting (height-for-age $Z$-score $<-2$ standard deviations) and obesity (BMI $\geq 95$ th percentile) were found to be major nutritional problems in children and adolescents. Stunting was prevalent in $10.7 \%$ of children and $12.4 \%$ of adolescents; $8.2 \%$ of children and 3.5\% of adolescents were obese. Adults were short (mean: $155.8 \mathrm{~cm}$ ) and values of overweight $(32.3 \%)$, obesity $(18.3 \%)$ and central adiposity (mean WC: $86.5 \mathrm{~cm}$ ) were high. Older adults and those with higher economic development showed higher prevalence of obesity and central adiposity.

Conclusions: The present population may be at the early stages of nutritional transition as symptoms of undernutrition and overnutrition coexist at the population level. These results suggest that rates of growth retardation may be decreasing owing to improved nutritional conditions; however, this could be accompanied by a sharp increase in the prevalence of other diet-related chronic diseases.
\end{abstract}

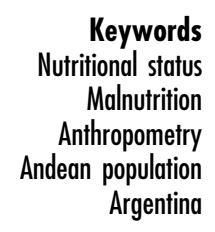

Puna and Quebrada of Humahuaca are two regions located in the Andean zone of the province of Jujuy (north-western Argentina) at the intersection of Chile, Bolivia and Argentina. The current population of Puna and Quebrada are descendants of different indigenous ethnic groups living in north-western Argentina and Bolivia (Diaguitas, Cochinhucas, Omaguacas, Atacamas, Quechua and Aimara). Quebrada of Humahuaca is a narrow and fertile mountain valley about $155 \mathrm{~km}$ long, oriented north-south. The region has always been a crossroad for economic, social and cultural communication. It can be divided into three climatic regions, a humid one with subtropical vegetation at around $1500 \mathrm{~m}$ above sea level and two arid regions up to $3300 \mathrm{~m}$ above sea level. The main economic activities are agriculture, grazing, tourism and a few extractive industries. Puna is an arid highland region shared by Argentina and Bolivia located at $3500 \mathrm{~m}$ above sea level on average. It is a cold high plain with several ranges that form closed basins where the rivers end in small lakes and salt deposits. The vegetation is sparse and the climate is dry and harsh, with high daily thermal oscillations. Grazing of sheep, goats and llamas are major economic activities. Agriculture is limited to family subsistence crops ${ }^{1}$.

Despite the adverse climatic conditions of the area, it has been inhabited for more than 10000 years and ancient dwellers developed advanced production and subsistence systems of agriculture, grazing and exchange. These permitted optimal use of the available foods and adequate physical and psychological development of the pre-columbine Andean population ${ }^{2}$. Nowadays, the ancient ability to cope with adverse environmental 
conditions and to grow and preserve foods seems to be disappearing. Urbanisation and globalisation in combination with low incomes are leading to the replacement of local foods by cheap, energy-dense, nutrient-poor foods such as refined grains, processed foods and foods rich in fat, sugar and salt (most times subsidised by national food and nutrition policies). Also, women frequently join the labour force and become less available to care for food security at home.

This phenomenon of modification of individual feeding practices as a consequence of change in economic, social, demographic and health structures has been reported in many lower- and middle-income countries and has been termed the 'nutrition transition'. The main consequence of the nutrition transition is a shift from a high prevalence of undernutrition to a predominance of diet-related chronic diseases ${ }^{3}$.

The nutritional situation of a country undergoing the nutrition transition depends on its economic development and transitional stage. Accordingly, different situations have been reported in Latin American countries: some countries show no increase in excess weight prevalence but high rates of growth retardation such as in Honduras; other countries show an increase in the prevalence of excess weight whereas malnutrition problems have almost disappeared (the case of Chile); in countries such as Peru, Bolivia, Nicaragua and Guatemala, there is a trend towards an increase in the rate of excess weight in adults but not so much in children while maintaining the high levels of undernutrition and growth retardation in the youngest population ${ }^{3-5}$. This last situation reflects rapid nutritional transition and symptoms of under- and overnutrition coexist not only at the population level (double burden of disease) but also in the same household (double-burden household) ${ }^{3,6}$.

Changes in food habits and physical activity patterns explain in part these dual-burden phenomena. The quality of new foods introduced in the diet, most times rich in energy but poor in nutrients, may adversely affect the growth of a child but provide sufficient calories for an adult to gain excess weight ${ }^{7}$. Also, nutritional interventions aimed to address the problem of malnutrition of one member of the household by increasing food availability may put the rest of the family at risk of excess weight ${ }^{6,8}$. Moreover, other biological factors unique in developing countries might exacerbate the effects of these ecological factors 9 . The possible explanation for why so many people become obese under such circumstances might have its origin in evolutionary roots. The 'thrifty genotype' hypothesis proposes that individuals adapted to chronic famine might increase their susceptibility to hoard calories as fat in times of abundance and develop obesity $^{4,5,10}$. Other theories link low birth weight with a higher predisposition to becoming obese (together with a higher risk of abdominal obesity, insulin resistance, glucose intolerance, dyslipidaemia and hypertension) ${ }^{4,10,11}$.
Childhood stunting may represent another pathway that predisposes children of developing countries to subsequent obesity ${ }^{4,10-14}$.

The objective of the present study was to investigate the nutritional status of the Andean population of Jujuy by performing anthropometric measurements in children, adolescents and adults, in order to test the hypothesis of the coexistence of undernutrition and obesity in this population facing the nutrition transition.

\section{Material and methods}

The present study is a population-based, cross-sectional nutritional survey carried out in the Andean regions of Puna and Quebrada of Humahuaca, in the province of Jujuy, Argentina. The fieldwork was carried out from May to December of 2005.

\section{Population}

The target population consisted of all inhabitants living in Puna and Quebrada regions (82 922 individuals according to the national census, 2000) ${ }^{15}$. The theoretical sample size was set at 500 families comprising 1500 individuals (it was planned to interview roughly three individuals in each family) in order to provide a specific relative precision of $5 \%$ (type I error $=0.05$; type II error $=0.10$ ), a design effect of 2 to account for the cluster sampling procedure and taking into account an anticipated 70\% participation rate. All interviewed individuals within a family had to belong to different sex (male or female) and age group (children, adolescents, adults); if there were two or more individuals from the same sex and age group within a house, one of them was randomly selected for data collection. The selection of the sample was done by stratified random cluster sampling procedures.

\section{Questionnaire}

A questionnaire divided into two parts was designed for the present study. The first questionnaire was intended to gather general information on the whole family and comprised questions related to household status, socioeconomic level of the family, educational level of the head of the household, food supply and security, and access to health-care systems. This first questionnaire was answered by an adult member of each household. The second part was specific for each member of the household participating in the study. This included questions related to individual educational level, health status, dietary habits, physical activity pattern and a nutritional survey (one 24-hour recall and a short food-frequency questionnaire). Also, specific questions for children $<5$ years of age and pregnant women were included in the questionnaire. These questionnaires were tested for reliability and suitability in two populations of Puna and 
Quebrada (95 individuals) before the beginning of the study. A group of well-trained interviewers carried out the fieldwork.

\section{Antbropometric measurements}

Anthropometric measures were taken of children of 2-9 years old, adolescents (10-17 years old) and adults (18 years old and above). The anthropometric measures used in this study were: height, weight, mid-upper-arm circumference (MUAC), waist circumference (WC), hip circumference (HC) and blood pressure (BP). Height, weight and MUAC were taken of children, adolescents and adults. WC, HC and BP were measured only in adults.

Height was determined using a mobile anthropometer (Kawe 44444) to the nearest $\mathrm{mm}$, with the subject's head in the Frankfurt plane. Body weight was determined to the nearest $100 \mathrm{~g}$ using a digital scale (Tefal charm, sc 2504). The subjects were weighed after taking off shoes and heavy clothes (the rest of the clothes were accounted for by subtracting $200 \mathrm{~g}$ in children and $400 \mathrm{~g}$ in adults from the measured weight). MUAC, WC and HC were measured using a non-stretchable measuring tape (Kawe 43972). MUAC (midpoint between acrimial and olecranon processes) was measured to the nearest $0.1 \mathrm{~cm}$ with the examinee's left arm relaxed. WC was measured at the navel in men, and midway between the bottom of the ribs and the top of the hip bone in women. HC was measured at the tip of the hip bone in men, and at the widest point between the hips and the buttocks in women. BP was measured using automated blood pressure machines (Omron No. RX3 Plus).

Anthropometric measurements were carried out according to Frisancho's recommendations ${ }^{16}$.

\section{Nutritional status assessment}

Stunted children and adolescents were identified as those with a height-for-age $Z$-score $<-2$ standard deviations (SD) of the World Health Organization/National Center for Health Statistics/Centers for Disease Control and Prevention (WHO/NCHS/CDC) reference standards. Wasting in children was defined as weight-for-height $Z$-score $<-2 \mathrm{SD}$ of the WHO/NCHS/CDC reference standards. In adolescents, thinness was defined as a body mass index (BMI; $\mathrm{kg} \mathrm{m}^{-2}$ ) for age $<5$ th percentile of the WHO/ NCHS/CDC reference standards. Overweight in children was defined as a weight-for-height $Z$-score $>1-2 \mathrm{SD}$ and obesity as weight-for-height $Z$-score $>2 \mathrm{SD}$ of the WHO/ NCHS/CDC reference standards, whereas in adolescents BMI-for-age between the 85th and 95th percentiles indicated overweight and BMI-for-age $\geq 95$ th percentile indicated obesity. Also, the weight-for-height status of children was assessed according to BMI-for-age as it was done with adolescents (BMI cut-off points: $<5$ th percentile indicating thinness; 85 th-95th percentile indicating overweight; $\geq 95$ th percentile indicating obesity) ${ }^{17-19}$.
The nutritional status of adults was determined according to BMI using the WHO classification ${ }^{20}$ (underweight defined as $\mathrm{BMI}<18.5 \mathrm{~kg} \mathrm{~m}^{-2}$; normal weight as BMI between 18.5 and $24.9 \mathrm{~kg} \mathrm{~m}^{-2}$; overweight as BMI between 25.0 and $29.9 \mathrm{~kg} \mathrm{~m}^{-2}$; obesity as BMI $>30 \mathrm{~kg} \mathrm{~m}^{-2}$ ). WC and waist-to-hip ratio (WHR) cut-off limits for men and women, described elsewhere ${ }^{21,22}$, were also considered to assess central fat deposition. Hypertension was identified when diastolic/systolic blood pressure was above 90/140 $\mathrm{mmHg}$.

\section{Sociodemographic characteristics}

The sociodemographic variables considered in the present study as possible determinants of the nutritional status were: gender, age, area (urban, suburban and rural), socio-economic status, food supply and security, and household status.

Socio-economic status was assessed according to the following variables: occupational level of the head of the household codified as low, medium or high according to the methodology described by the National Institute of Statistics and Censuses ${ }^{15}$; educational level of the head of the household classified as low (none or primary school incomplete), medium (primary school complete or secondary school incomplete) or high (secondary school complete or university degree); and level of poverty according to estimated US\$ per person per day (extreme poverty - less than US\$1 per person per day; poverty less than US\$2 per person per day; above poverty threshold - more than US\$2 per person per day). Gross US\$ per person per day was estimated by dividing the total monthly income of the household by the number of family members and by 30 .

The questions related to food supply and security considered in the present study were: receiving food aids from government (yes/no); production of food in the household (yes/no); and use of food preservation techniques (yes/no).

Household status was assessed according to seven variables about the sanitation and hygienic conditions of the household (type of floor; number of rooms; electricity; toilets; waste pipe; separate kitchen; and drinkable water). A household status score (HSS) was constructed in order to facilitate the analysis. Each category of these seven variables received points to construct the composite HSS (score range 0-7). Information about the scoring system is illustrated in Table 1.

\section{Statistical analysis}

Nutritional data of subjects aged 2-17 years were analysed using Epi-Info (CDC), which is based on age, gender, height and weight and provides the height-forage, weight-for-height, and BMI-for-age indices, both in percentiles and Z-scores. 
Table 1 Sociodemographic characteristics of the whole sample from the Andean region of Jujuy, and separately by region (Quebrada and Puna)

\begin{tabular}{|c|c|c|c|c|}
\hline & $\begin{array}{c}\text { All }(n=1236) \\
\%\end{array}$ & $\begin{array}{c}\text { Quebrada }(n=587) \\
\%\end{array}$ & $\begin{array}{c}\text { Puna }(n=649) \\
\%\end{array}$ & $P$-value* \\
\hline \multicolumn{5}{|l|}{ Area } \\
\hline Urban & 53.2 & 52.7 & 53.6 & \multirow[t]{3}{*}{0.538} \\
\hline Suburban & 18.0 & 19.2 & 16.8 & \\
\hline Rural & 28.9 & 28.1 & 29.6 & \\
\hline \multicolumn{5}{|l|}{ Occupation level of household head } \\
\hline Low & 70.0 & 72.9 & 67.4 & \multirow[t]{3}{*}{0.018} \\
\hline Medium & 26.3 & 22.6 & 29.5 & \\
\hline High & 3.7 & 4.6 & 3.0 & \\
\hline \multicolumn{5}{|l|}{ Education level of household head } \\
\hline Low & 27.6 & 29.9 & 25.5 & \multirow[t]{3}{*}{0.085} \\
\hline Medium & 58.3 & 57.9 & 58.6 & \\
\hline High & 14.2 & 12.2 & 16.0 & \\
\hline \multicolumn{5}{|l|}{ Level of poverty } \\
\hline Extreme poverty ( $<$ US $\$ 1$ per person per day) & 81.7 & 83.2 & 80.4 & \multirow[t]{3}{*}{0.461} \\
\hline Poverty (<US $\$ 2$ per person per day) & 12.8 & 11.6 & 13.8 & \\
\hline Above poverty & 5.5 & 5.2 & 5.8 & \\
\hline \multicolumn{5}{|l|}{ Receive food aids from government } \\
\hline No & 32.0 & 37.4 & 27.0 & \multirow[t]{2}{*}{0.000} \\
\hline Yes & 68.0 & 62.6 & 73.0 & \\
\hline \multicolumn{5}{|l|}{ Produce food in the household } \\
\hline No & 49.3 & 41.9 & 56.1 & \multirow[t]{2}{*}{0.000} \\
\hline Yes & 50.7 & 58.1 & 43.9 & \\
\hline \multicolumn{5}{|l|}{ Use food preservation techniques } \\
\hline No & 45.2 & 41.4 & 48.8 & \multirow[t]{2}{*}{0.012} \\
\hline Yes & 54.8 & 58.6 & 51.2 & \\
\hline \multicolumn{5}{|l|}{ Type of floort } \\
\hline No - soil $(=0)$ & 37.3 & 46.5 & 29.0 & \multirow[t]{2}{*}{0.000} \\
\hline Yes - cement, wood, etc. $(=1)$ & 62.7 & 53.5 & 71.0 & \\
\hline \multicolumn{5}{|l|}{ Number of roomst } \\
\hline $1(=0)$ & 26.5 & 23.3 & 29.4 & \multirow[t]{3}{*}{0.053} \\
\hline $2-3(=0.5)$ & 49.7 & 50.9 & 48.7 & \\
\hline$>3(=1)$ & 23.8 & 25.8 & 22.0 & \\
\hline \multicolumn{5}{|l|}{ Electricity } \\
\hline No $(=0)$ & 15.8 & 22.6 & 9.7 & \multirow[t]{3}{*}{0.000} \\
\hline Solar energy $(=0.5)$ & 2.1 & 3.5 & 0.8 & \\
\hline Yes $(=1)$ & 82.1 & 73.9 & 89.5 & \\
\hline \multicolumn{5}{|l|}{ Toiletst } \\
\hline No $(=0)$ & 6.9 & 4.8 & 8.8 & 0.017 \\
\hline Latrine $(=0.5)$ & 48.7 & 51.2 & 46.4 & \\
\hline Yes $(=1)$ & 44.4 & 44.0 & 44.8 & \\
\hline Waste pipet & & & & \\
\hline No $(=0)$ & 55.4 & 55.0 & 55.7 & 0.002 \\
\hline Septic tank $(=0.5)$ & 21.3 & 17.8 & 24.5 & \\
\hline Yes $(=1)$ & 23.3 & 27.1 & 19.8 & \\
\hline Separate kitchent & & & & \\
\hline No $(=0)$ & 18.0 & 17.1 & 18.9 & 0.435 \\
\hline Yes $(=1)$ & 82.0 & 82.9 & 81.1 & \\
\hline Drinkable watert & & & & \\
\hline No $(=0)$ & 13.4 & 26.6 & 5.8 & 0.000 \\
\hline Yes $(=1)$ & 86.6 & 73.4 & 94.2 & \\
\hline
\end{tabular}

*Level of significance of the observed differences between Puna and the Quebrada by means of the $\chi^{2}$ test.

+ Variables used to construct the household status score (HSS). The points given to each category is shown in brackets. The total score range is $0-7$.

The rest of the analyses were performed with SPSS version 13.0 (SPSS Inc.). The study was carried out separately in children, adolescents and adults. Significant differences in percentages between groups were calculated by means of the $\chi^{2}$ test. Multiple logistic regression models, with calculation of corresponding adjusted odds ratios and 95\% confidence intervals, were used to examine the sociodemographic determinants of major nutritional problems observed in children, adolescents and adults. Differences were regarded as significant when the $P$-value was $<0.05$.

\section{Results}

The final sample comprised 1236 individuals aged 0-86 years (359 families; response rate of $72 \%$ ). Nonparticipation rates included potential subjects declining to be interviewed as well as involuntary non-participation due to census error caused by address changes, missing persons or unavoidable impediments to survey collaboration.

For the present study only children aged $2-9$ years $(n=369)$, adolescents aged $10-17$ years $(n=210)$ and 
adults ( $\geq 18$ years old) excluding pregnant and lactating women $(n=478)$ were included. The sampling technique permitted us to obtain a representative sample of each region (Puna and Quebrada) proportionally distributed over the three areas (urban, suburban and rural).

Table 1 shows the sociodemographic characteristics of the whole sample and separately by region. Overall socio-economic status was very low and most of the sample had to receive food aids from government. Some differences in sociodemographic characteristics were observed between Puna and Quebrada. The occupational level of the head of the household was lower in Quebrada compared with Puna, although no differences were observed in the educational level and income. Individuals from Puna relied more on food aids from government than individuals from Quebrada, whereas individuals from Quebrada were more likely to produce and preserve foods. Also some differences were observed in household status characteristics. Overall, the HSS was slightly greater in Puna (mean 4.81; SD 1.37) than in Quebrada (mean 4.52; SD 1.72) ( $P=0.04$; data not shown).

Table 2 shows mean values of anthropometric measurements in children and adolescents by sex. Also shown are prevalences of stunting, wasting, overweight and obesity according to different indices. Stunting was observed in $10.7 \%$ of children. Wasting (weight-for-height $<-2$ SD) was observed in $3.2 \%$ of the sample. Some $5.9 \%$ of children showed a BMI-for-age $<5$ th percentile. The prevalence of overweight and obesity in children differed according to the criteria used to define them. Prevalence of overweight defined as weight-for-height $>1-2 \mathrm{SD}$ was observed in $19.7 \%$ of the sample, whereas the prevalence of children with a BMI-for-age between the 85th and 95th percentile was $13.8 \%$. Obesity as weight-for-height $>2 \mathrm{SD}$ was observed in $3.2 \%$ of children; on the other hand, obesity as BMI-for-age $\geq 95$ th percentile was observed in
$8.2 \%$ of the sample. Of adolescents, $12.4 \%$ were stunted; according to BMI-for-age, $6.9 \%$ were thin $(<5$ th percentile), $10.9 \%$ were overweight ( 85 th to $<95$ th percentile) and $3.5 \%$ were obese ( $\geq 95$ th percentile).

The sociodemographic determinants of stunting in children and adolescents are shown in Table 3. Multiple logistic regression models considering the simultaneous effect of all variables were used for the present analysis. Age was a strong determinant of stunting in both children and adolescents: the older the individual, the higher the odds of being stunted. Children from Puna also showed higher odds of being stunted, but this trend was not observed in adolescents. The same type of analysis was performed to ascertain the sociodemographic determinants of wasting, overweight and obesity in both children and adolescents, but no statistically significant associations were found (data not shown).

Table 4 shows the average values of anthropometric measurements and indices applied to the adult population. Mean BMI was 25.9 (SD 5.4) $\mathrm{kg} \mathrm{m}^{-2}$ and average prevalence of overweight and obesity was $32.3 \%$ and $18.3 \%$, respectively. A higher percentage of males (37.2\%) than females (29.4\%) were overweight but females showed greater prevalence of obesity (22.6\%) compared with males (10.9\%). Only $1.0 \%$ of the sample was undernourished according to BMI $\left(<18.5 \mathrm{~kg} \mathrm{~m}^{-2}\right)$. Hypertension was observed in $12.9 \%$ of males and $6.5 \%$ of females. Females showed significantly higher central fat deposition according to both WC (39.9\% of females) and WHR (25.8\% of females) than males (8.9\% and 6.0\% of males showed WC and WHR values above the cut-off point).

Table 5 shows the sociodemographic determinants of obesity and central adiposity (according to WC). Age was a strong determinant of these three conditions. Central adiposity was strongly associated with female sex. The

Table 2 Anthropometric measurements and nutritional status of children and adolescents from Puna and Quebrada

\begin{tabular}{|c|c|c|c|c|c|c|}
\hline & \multicolumn{3}{|c|}{ Children (2-9 years) } & \multicolumn{3}{|c|}{ Adolescents (10-17 years) } \\
\hline & $\begin{array}{c}\text { All } \\
(n=369)\end{array}$ & $\begin{array}{c}\text { Males } \\
(n=188)\end{array}$ & $\begin{array}{l}\text { Females } \\
(n=181)\end{array}$ & $\begin{array}{c}\text { All } \\
(n=210)\end{array}$ & $\begin{array}{c}\text { Males } \\
(n=94)\end{array}$ & $\begin{array}{l}\text { Females } \\
(n=116)\end{array}$ \\
\hline Age (years)* & $5.1 \pm 2.2$ & $5.1 \pm 2.2$ & $5.2 \pm 2.2$ & $12.7 \pm 2.3$ & $12.4 \pm 2.1$ & $12.9 \pm 2.3$ \\
\hline Weight $(\mathrm{kg})^{\star}$ & $18.8 \pm 5.8$ & $19.1 \pm 5.7$ & $18.6 \pm 5.8$ & $41.6 \pm 11.1$ & $40.7 \pm 10.7$ & $42.3 \pm 11.3$ \\
\hline Height $(\mathrm{cm})^{\star}$ & $107.3 \pm 15.6$ & $107.2 \pm 15.2$ & $107.4 \pm 16.0$ & $146.5 \pm 12.5$ & $147.4 \pm 12.4$ & $145.8 \pm 12.5$ \\
\hline $\operatorname{MUAC}(\mathrm{cm})^{*}$ & $16.2 \pm 1.9$ & $16.3 \pm 1.8$ & $16.1 \pm 2.0$ & $21.1 \pm 3.1$ & $20.8 \pm 2.7$ & $21.3 \pm 3.4$ \\
\hline \multicolumn{7}{|l|}{ Height-for-aget } \\
\hline$<-2$ SD (stunting) & 10.7 & 10.1 & 11.4 & 12.4 & 14.3 & 10.9 \\
\hline \multicolumn{7}{|l|}{ Weight-for-height ${ }^{\prime}$} \\
\hline$<-2 S D$ (wasting) & 3.2 & 1.4 & 4.9 & & & \\
\hline$>1-2 S D$ (overweight) & 19.7 & 15.6 & 23.8 & & & \\
\hline$>2 \mathrm{SD}$ (obesity) & 3.2 & 2.1 & 4.2 & & & \\
\hline \multicolumn{7}{|l|}{ BMI-for-aget } \\
\hline$<5$ th percentile (thinness) & 5.9 & 6.0 & 5.8 & 6.9 & 7.6 & 6.4 \\
\hline 85th $-<95$ th percentile (overweight) & 13.8 & 16.3 & 11.1 & 10.9 & 10.9 & 10.9 \\
\hline$\geq 95$ th percentile (obesity) & 8.2 & 7.1 & 9.4 & 3.5 & 1.1 & 5.5 \\
\hline
\end{tabular}

MAUC - mid upper-arm circumference; SD - standard deviation; BMI - body mass index.

*Values shown are mean \pm SD.

†Values shown are \%. 
Table 3 Sociodemographic determinants of stunting in children (2-9 years) and adolescents (10-17 years) from Puna and Quebrada

\begin{tabular}{|c|c|c|c|c|}
\hline & \multicolumn{2}{|l|}{ Children } & \multicolumn{2}{|c|}{ Adolescents } \\
\hline & Adjusted OR $(95 \% \mathrm{Cl})$ & $P$-value & Adjusted OR (95\% Cl) & $P$-value \\
\hline \multicolumn{5}{|l|}{ Gender } \\
\hline Male & $0.49(0.21-1.15)$ & 0.102 & $2.35(0.75-7.32)$ & 0.141 \\
\hline Female & 1.00 (referent) & & 1.00 (referent) & \\
\hline \multicolumn{5}{|l|}{ Age (continuous) } \\
\hline (1-year increase) & $1.21(1.00-1.46)$ & 0.045 & $1.38(1.06-1.80)$ & 0.016 \\
\hline \multicolumn{5}{|l|}{ Area } \\
\hline Urban & $0.37(0.13-1.04)$ & 0.059 & $1.06(0.25-4.51)$ & 0.939 \\
\hline Suburban & $0.08(0.01-0.79)$ & 0.031 & $0.63(0.06-7.13)$ & 0.706 \\
\hline Rural & 1.00 (referent) & & 1.00 (referent) & \\
\hline \multicolumn{5}{|l|}{ Region } \\
\hline Quebrada & $0.21(0.07-0.63)$ & 0.005 & $0.44(0.11-1.73)$ & 0.243 \\
\hline Puna & 1.00 (referent) & & 1.00 (referent) & \\
\hline \multicolumn{5}{|l|}{ HSS (continuous) } \\
\hline (1-point increase) & $1.09(0.79-1.51)$ & 0.587 & $1.28(0.84-1.94)$ & 0.253 \\
\hline \multicolumn{5}{|l|}{ Occupation level of household head } \\
\hline Low & $1.08(0.42-2.80)$ & 0.877 & $4.21(0.82-21.8)$ & 0.086 \\
\hline Medium/high & 1.00 (referent) & & 1.00 (referent) & \\
\hline \multicolumn{5}{|l|}{ Education level of household head } \\
\hline Low & $3.53(0.58-21.3)$ & 0.169 & $1.04(0.14-7.51)$ & 0.967 \\
\hline Medium & $3.29(0.62-17.5)$ & 0.164 & $0.78(0.13-4.86)$ & 0.791 \\
\hline High & 1.00 (referent) & & 1.00 (referent) & \\
\hline \multicolumn{5}{|l|}{ Income (continuous) } \\
\hline (US\$1 per person per day increase) & $0.40(0.10-1.63)$ & 0.202 & $0.16(0.02-1.28)$ & 0.084 \\
\hline \multicolumn{5}{|l|}{ Receive food aids from government } \\
\hline No & $2.46(0.92-6.58)$ & 0.074 & $1.07(0.25-4.48)$ & 0.926 \\
\hline Yes & 1.00 (referent) & & 1.00 (referent) & \\
\hline \multicolumn{5}{|l|}{ Produce food in the household } \\
\hline No & $2.65(1.01-6.93)$ & 0.048 & $1.09(0.31-3.89)$ & 0.896 \\
\hline Yes & 1.00 (referent) & & 1.00 (referent) & \\
\hline \multicolumn{5}{|l|}{ Use food preservation techniques } \\
\hline No & $1.64(0.64-4.18)$ & 0.302 & $0.21(0.06-0.78)$ & 0.019 \\
\hline Yes & 1.00 (referent) & & 1.00 (referent) & \\
\hline
\end{tabular}

OR - odds ratio; $\mathrm{Cl}$ - confidence interval; HSS - household status score.

Multiple logistic regression analyses considering the simultaneous effect of all sociodemographic variables on the probability of being stunted in children and adolescents.

Table 4 Anthropometric measurements and nutritional status of adults ( $\geq 18$ years old) from Puna and Quebrada, by gender

\begin{tabular}{|c|c|c|c|}
\hline & All $(n=478)$ & Males $(n=184)$ & Females $(n=294)$ \\
\hline Age (years)* & $40.1 \pm 15.6$ & $39.0 \pm 15.5$ & $40.8 \pm 15.7$ \\
\hline Weight $(\mathrm{kg})^{\star}$ & $62.5 \pm 12.9$ & $66.9 \pm 12.5$ & $59.8 \pm 12.4$ \\
\hline Height $(\mathrm{cm})^{*}$ & $155.8 \pm 10.8$ & $162.3 \pm 13.8$ & $151.8 \pm 5.4$ \\
\hline BMI $\left(\mathrm{kg} \mathrm{m}^{-2}\right)^{\star}$ & $25.9 \pm 5.4$ & $25.2 \pm 4.0$ & $26.3 \pm 6.0$ \\
\hline $\mathrm{WC}(\mathrm{cm})^{*}$ & $86.5 \pm 11.8$ & $87.6 \pm 11.2$ & $85.8 \pm 12.1$ \\
\hline $\mathrm{HC}(\mathrm{cm})^{*}$ & $98.1 \pm 10.4$ & $96.3 \pm 8.7$ & $99.2 \pm 11.1$ \\
\hline $\mathrm{WHR}^{\star}$ & $0.9 \pm 0.2$ & $0.9 \pm 0.2$ & $0.9 \pm 0.1$ \\
\hline $\operatorname{MUAC}(\mathrm{cm})^{*}$ & $26.7 \pm 3.7$ & $27.0 \pm 2.7$ & $26.4 \pm 4.1$ \\
\hline Diastolic BP $\left(\mathrm{mmHg}^{*}\right.$ & $77.8 \pm 12.3$ & $80.9 \pm 11.3$ & $75.9 \pm 12.6$ \\
\hline Systolic BP $(\mathrm{mmHg})^{\star}$ & $124.0 \pm 20.5$ & $128.5 \pm 18.1$ & $121.2 \pm 21.4$ \\
\hline Low weighttł & 1.0 & 0.6 & 1.1 \\
\hline Overweighttł & 32.3 & 37.2 & 29.4 \\
\hline Obesitytł & 18.3 & 10.9 & 22.6 \\
\hline Central adiposity $(\mathrm{WC})+\S$ & 28.1 & 8.9 & 39.9 \\
\hline Central adiposity (WHR)+ & 18.2 & 6.0 & 25.8 \\
\hline Hypertensiont\| & 8.9 & 12.9 & 6.5 \\
\hline
\end{tabular}

BMI - body mass index; WC - waist circumference; HC - hip circumference; WHR - waist-to-hip ratio; MAUC - mid upper-arm circumference; BP - blood pressure.

*Values shown are mean \pm standard deviation.

†Values shown are \%.

$\ddagger$ BMI cut-off points were used to classify individuals as undernourished (low weight, $\left.<18.5 \mathrm{~kg} \mathrm{~m}^{-2}\right)$, overweight $\left(25.0-29.9 \mathrm{~kg} \mathrm{~m}^{-2}\right)$ and obese $\left(>30 \mathrm{~kg} \mathrm{~m}^{-2}\right.$ ).

$\S$ Cut-off limits of central adiposity: WC $>102 \mathrm{~cm}$ in men, WC $>88 \mathrm{~cm}$ in women ${ }^{21,22}$.

- Cut-off limits of central adiposity: WHR $>1.00$ in men, WHR $>0.90$ in women ${ }^{21,22}$

$\|$ Hypertension was defined as diastolic BP $>90 \mathrm{mmHg}$ and systolic BP $>140 \mathrm{mmHg}$. 
Table 5 Sociodemographic determinants of obesity and central adiposity in adults ( $\geq 18$ years old) from Puna and Quebrada

\begin{tabular}{|c|c|c|c|c|}
\hline & \multicolumn{2}{|l|}{ Obesity } & \multicolumn{2}{|c|}{ Central adiposity (WC) } \\
\hline & Adjusted OR $(95 \% \mathrm{Cl})$ & $P$-value & Adjusted OR (95\% Cl) & $P$-value \\
\hline \multicolumn{5}{|l|}{ Gender } \\
\hline Male & $0.57(0.27-1.18)$ & 0.129 & $0.17(0.08-0.33)$ & 0.000 \\
\hline Female & 1.00 (referent) & & 1.00 (referent) & \\
\hline \multicolumn{5}{|l|}{ Age (continuous) } \\
\hline (1-year increase) & $1.04(1.01-1.06)$ & 0.006 & $1.03(1.01-1.05)$ & 0.008 \\
\hline \multicolumn{5}{|l|}{ Area } \\
\hline Urban & $2.56(0.94-6.94)$ & 0.066 & $1.70(0.77-3.77)$ & 0.190 \\
\hline Suburban & $1.55(0.46-5.24)$ & 0.478 & $1.61(0.61-4.26)$ & 0.340 \\
\hline Rural & 1.00 (referent) & & 1.00 (referent) & \\
\hline \multicolumn{5}{|l|}{ Region } \\
\hline Quebrada & $0.99(0.48-2.04)$ & 0.988 & $1.25(0.69-2.26)$ & 0.459 \\
\hline Puna & 1.00 (referent) & & 1.00 (referent) & \\
\hline \multicolumn{5}{|l|}{ HSS (continuous) } \\
\hline (1-point increase) & $1.67(1.23-2.27)$ & 0.001 & $1.53(1.19-1.96)$ & 0.001 \\
\hline \multicolumn{5}{|l|}{ Occupation level of household head } \\
\hline Low & $1.81(0.84-3.89)$ & 0.129 & $1.46(0.77-2.76)$ & 0.249 \\
\hline Medium/high & 1.00 (referent) & & 1.00 (referent) & \\
\hline \multicolumn{5}{|l|}{ Education level of household head } \\
\hline Low & $1.38(0.44-4.34)$ & 0.581 & $1.94(0.77-4.93)$ & 0.162 \\
\hline Medium & $0.76(0.27-2.14)$ & 0.606 & $0.96(0.42-2.20)$ & 0.921 \\
\hline High & 1.00 (referent) & & 1.00 (referent) & \\
\hline \multicolumn{5}{|l|}{ Income (continuous) } \\
\hline (US\$1 per person per day increase) & $0.76(0.43-1.34)$ & 0.336 & $0.78(0.51-1.20)$ & 0.264 \\
\hline \multicolumn{5}{|l|}{ Receive food aids from government } \\
\hline No & $1.17(0.55-2.47)$ & 0.691 & $1.23(0.65-2.32)$ & 0.534 \\
\hline Yes & 1.00 (referent) & & 1.00 (referent) & \\
\hline \multicolumn{5}{|l|}{ Produce food in the household } \\
\hline No & $0.85(0.40-1.82)$ & 0.682 & $0.91(0.49-1.72)$ & 0.779 \\
\hline Yes & 1.00 (referent) & & 1.00 (referent) & \\
\hline \multicolumn{5}{|l|}{ Use food preservation techniques } \\
\hline No & $0.97(0.49-1.95)$ & 0.943 & $1.14(0.64-2.01)$ & 0.665 \\
\hline Yes & 1.00 (referent) & & 1.00 (referent) & \\
\hline
\end{tabular}

WC - waist circumference; OR - odds ratio; $\mathrm{Cl}$ - confidence interval; HSS - household status score.

Multiple logistic regression analyses considering the simultaneous effect of all sociodemographic variables on the probability of obesity and central adiposity (according to WC cut-off points).

higher the HSS, the higher was the odds of showing obesity and central adiposity. Similar analyses were carried out to elucidate the determinants of overweight and central fat deposition according to WHR. Overweight was significantly associated only with age, whereas central adiposity was associated with female sex (data not shown).

\section{Discussion}

This cross-sectional study describes the nutritional status of a representative sample of inhabitants of the Andean regions of Jujuy, Argentina. Most of the population were indigenous and lived at high altitudes. Their socio-economic and educational statuses were low, and reported family income revealed that most of the sample lived under the poverty line. Production and preservation of foods in the household was more common in the region of Quebrada than in Puna, possibly because of the most propitious climatic conditions in the former region. Individuals from Puna were more likely to rely on food aids supplied by the government. The adverse climate together with the isolation conditions of many areas in Puna might explain these findings.

Compared with other studies that identified childhood overweight and obesity using weight-for-height $Z$-score cut-off points, the prevalence of overweight and obesity in children from this population is low in relation to other developing and developed countries and similar to that observed in less developed countries in Latin America $^{4,23-25}$. One study conducted in Argentina reported an obesity prevalence in children aged 24-72 months of $7.03 \%$, ranging from $2.3 \%$ to $17.0 \%$. The lowest prevalence of obesity, similar that observed in our study in the same age group, was found in Salta (a province bordering Jujuy) $)^{4,26}$.

Previous studies have reported that children and adolescents from Jujuy are among the shortest in Argentina. One study conducted in 6-7-year-old children from 12 provinces of Argentina (1991-1994) showed a prevalence of chronic malnutrition (height-for-age $<-2$ SD) of $11.8 \%$ in the province of Jujuy, the highest in the whole country $^{26}$. Similar values were observed in our sample. However, in relation to results obtained in other Latin American countries, the prevalence of stunting in our 
sample is low. The prevalence of stunting ranges from $45.5 \%$ in Guatemala to $8.9 \%$ in Dominican Republic, with values of $27.0 \%$ in Bolivia, $24.4 \%$ in Peru, $12.6 \%$ in Colombia and $9.5 \%$ in Brazil ${ }^{8}$. The proportion of stunting in the present sample is also low compared with results observed in studies conducted in other Andean areas (one study conducted in Ecuadorian Andes reported that more than $50 \%$ of children and adolescents were stunted ${ }^{27}$ ).

When the weight status of children and adolescents was compared (according to BMI-for-age) we observed that, on average, a much greater proportion of children were overweight and/or obese compared with adolescents. The 3-5-year age group was the one that showed the highest BMI-for-age values (obesity prevalence 13.3\%). In late childhood and early adolescence BMIfor-age values tended to be lower (the lowest obesity prevalence, $1.7 \%$, was observed in the $12-14$-year age group); the oldest age group of adolescents (16-18 years) showed again relatively high obesity prevalence (10.3\%) compared with other age groups. Stunting is likely to increase with age in children and adolescents. Adolescents from the oldest age group (16-18 years) were those who showed the highest prevalence of stunting (28.6\%). This association might be biased by the cross-sectional design of the study. Since stunting in adolescents reflects chronic undernutrition in the early years, it is possible that the nutritional situation of the population has improved over the years. Current feeding programmes targeting children, such as attendance to school canteens or the bag of foods given to malnourished children $<5$ years of age, might account for this improved situation. On the other hand, the observed situation in the group of 16-18-year-olds (high prevalence of both stunting and obesity) might reflect the double burden of malnutrition at the individual level.

Mean adult height in this population $(155 \mathrm{~cm})$ was slightly lower than the height of other Andean populations (Peruvian Quechua $158 \mathrm{~cm}$; Bolivian Aymara $161 \mathrm{~cm}$; Chilean Aymara $163 \mathrm{~cm})^{28}$. Mean adult weight in the present population $(62.5 \mathrm{~kg})$ was higher than in other Andean populations (Peruvian Quechua $60.3 \mathrm{~kg}$; Bolivian Aymara $57.1 \mathrm{~kg}$; Chilean Aymara $61.1 \mathrm{~kg}$ ), resulting in a higher BMI in our study sample $\left(25.9 \mathrm{~kg} \mathrm{~m}^{-2}\right)$ than in other Andean populations (e.g. $24.2 \mathrm{~kg} \mathrm{~m}^{-2}$ in Peruvian Quechua). Prevalence of overweight (32.3\%) and obesity $(18.3 \%)$ in the adult population was high and similar to that observed in other Latin American countries. Data from previous studies showed a prevalence of overweight of $34.1 \%$ in Argentina, 28.6\% in Brazil, $40.3 \%$ in Mexico, $38.8 \%$ in Paraguay and $41.3 \%$ in Peru. Obesity prevalence was $26.9 \%$ in Argentina, $19.7 \%$ in Chile, $20.0 \%$ in Mexico and $29.3 \%$ in Paraguay ${ }^{4}$. One study carried out with South American Indian groups, that defined obesity as BMI $>27 \mathrm{~kg} \mathrm{~m}^{-2}$, showed an obesity prevalence in rural adult Aymaras living in north Chile (geographically closer to the studied population) of $33 \%$. When the same cut-off was applied to the present adult population, the prevalence of

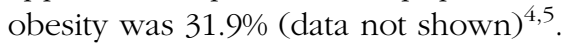

A link between socio-economic status, level of urbanisation and obesity has been found in countries emerging from poverty ${ }^{3,8,11,29}$, although this association tends to reverse as the country level of development improves ${ }^{5,24}$. In the present population household status was directly associated with obesity prevalence and central adiposity according to WC. No other indicator of socio-economic status was significantly associated with excess weight and central obesity. It is possible that in the present population the status of the household was the variable that better reflected the socio-economic condition of the family and level of development, given the overall low levels of education, occupation and income. Individuals from urban and suburban areas were at significantly higher risk of being obese compared with individuals from rural areas in the univariate analysis (data not shown), but this effect was no longer significant when the continuous variable HSS was introduced in the multiple logistic regression model. This was due to an interaction between the effect of HSS and area on the probability of being obese. There was a direct association between prevalence of obesity and area, but within each area level (rural, suburban and urban) the proportion of individuals with obesity was twofold greater when their HSS was above the median vs. those with HSS below the median (data not shown). These results suggest that factors leading to the nutrition transition associated with economic development are apparent in rural as well as urban areas, and so the distinction becomes not that between urban and rural but between more and less developed. Similar findings have been reported previously ${ }^{8}$.

Ecological and biological factors have been proposed as explanatory causes of the high rate of obesity observed in developing countries. However, it should be pointed out that weight-for-height may not reflect fatness in this population. Most validation studies using BMI as an indicator of fatness have been made in developed countries, and less attention has been paid to the use of BMI as an indicator of fatness in populations of developing countries ${ }^{4,10}$. Studies carried out to assess body size, structure and composition in Andean communities revealed that subjects tend to be shorter in relation to body weight; BMI values are near the median of the NHANES II (Second National Health and Nutrition Examination Survey) reference, but stature is near the 5th percentile. They show a long trunk relative to the lower extremities; values of subcutaneous adiposity are low, whereas arm circumference values are high ${ }^{28}$. Then, BMI might not be a good index of obesity in these populations. Also, possible selective increases in abdominal obesity in young stunted men and women must be considered $^{4,10}$. In the present study central adiposity and central fat deposition were high, mostly in women and older adults. 


\section{Conclusions}

Although no temporal trends can be ascertained and the determinants of nutritional status can only be hypothesised, this descriptive, cross-sectional study has permitted us to draw a picture of the current nutritional status of the Andean population of Puna and Quebrada of Humahuaca. These results demonstrate the presence of the double burden of malnutrition at the population level in this community. Chronic malnutrition and deprivation at the household level seemed to be major nutritional problems; they were reflected in the low values of height in children, adolescents and adults. On the other hand, obesity prevalence among certain groups of individuals (young children, old adolescents and adults) was also very high. The higher prevalence of stunting in adolescents than children might reflect improved nutritional conditions over the years in the region. Rates of both obesity and central adiposity in adults increased with level of development within the household, a typical trait of the nutrition transition in countries emerging from poverty. Ecological and biological factors might explain the observed nutritional status of this population. Sustainable intervention based on recuperation of ancient techniques of local food production and preservation, nutritional programmes targeting not only the under- $5 \mathrm{~s}$ but also adolescents, and nutritional education for the adult population aimed at preventing and solving major nutritional problems according to their level of development, should be considered.

\section{Acknowledgements}

This study was granted by the Spanish Agency for International Cooperation (AECI) and by the Cooperation and Immigration Ministry of the Balearic Islands Government. The authors are grateful to the Agents of Health Primary Attention, Ministry of Social Welfare, Province of Jujuy (Argentina). Special thanks go to A Rossi, C Miranda, C Pérez Martínez, J Gutiérrez, MA Jiménez, MD Juárez, S Burke, ME Acuña, S Chañi and E Jiménez. J.A.T., A.P. and N.S. were responsible for the study concept. J.A.T., A.P. and N.S. were responsible for the research design. N.S., D.R., N.F. and M.L. obtained data. D.R. carried out the data analyses and drafted the manuscript. J.A.T., N.S., A.P. and D.R. critically revised the article for intellectual content. None of the authors had a conflict of interest.

\section{References}

1 Salomon F, Schwartz S. The Cambridge History of the Native Peoples of the Americas (2-part set). Cambridge: Cambridge University Press, 1999.

2 Valda M, Cajias M. De como se alimentaban nuestros antepasados antes de la llegada de los españoles. Memoria Historica MH-7. La Paz: Hisbol, 1992.
3 Rivera JA, Barquera S, González-Cossío T, Olaiz G, Sepúlveda J. Nutrition transition in Mexico and in other Latin American countries. Nutrition Reviews 2004; 62(7 Pt 2): S149-57.

4 Filozof C, Gonzalez C, Sereday M, Mazza C, Braguinsky J. Obesity prevalence and trends in Latin-American countries. Obesity Reviews 2001; 2(2): 99-106.

5 Uauy R, Albala C, Kain J. Obesity trends in Latin America: transiting from under- to overweight. Journal of Nutrition 2001; 131(3): 893S-9S.

6 Doak CM, Adair LS, Bentley M, Monteiro C, Popkin BM. The dual burden household and the nutrition transition paradox. International Journal of Obesity 2005; 29(1): 129-36.

7 Caballero B. A nutrition paradox - underweight and obesity in developing countries. New England Journal of Medicine 2005; 352(15): 1514-16.

8 Garrett JL, Ruel MT. Stunted child-overweight mother pairs: prevalence and association with economic development and urbanization. Food and Nutrition Bulletin 2005; 26(2): 209-21.

9 Popkin BM. The nutrition transition: an overview of world patterns of change. Nutrition Reviews 2004; 62(7 Pt 2): S140-3.

10 Caballero B. Introduction. Symposium: Obesity in developing countries: biological and ecological factors. Journal of Nutrition 2001; 131(3): 866S-70S.

11 Florêncio TM, Ferreira HS, de França AP, Cavalcante JC, Sawaya AL. Obesity and undernutrition in a very-lowincome population in the city of Maceio, northeastern Brazil. British Journal of Nutrition 2001; 86(2): 277-84.

12 Popkin BM, Richards MK, Montiero CA. Stunting is associated with overweight in children of four nations that are undergoing the nutrition transition. Journal of Nutrition 1996; 126(12): 3009-16.

13 Hoffman D, Sawaya AL, Verreschi I, Tucker KL, Roberts SB. Why are nutritionally stunted children at increased risk of obesity? Studies of metabolic rate and fat oxidation in shantytown children from Sao Paulo, Brazil. American Journal of Clinical Nutrition 2000; 72(3): 702-7.

14 Schroeder DG, Martorell R, Flores R. Infant and child growth and fatness and fat distribution in Guatemalan adults. American Journal of Epidemiology 1999; 149(2): $177-85$.

15 National Institute of Statistics and Censuses. Indicores demográficos por provincias [online], 2000. Available at http://www.indec.mecon.ar. Accessed 21 July 2006.

16 Frisancho A. Anthropometric Standards for the Assessment of Growth and Nutritional Status. Ann Arbor, MI: University of Michigan Press, 1990.

17 World Health Organization (WHO). Measurement of Nutritional Impact. Geneva: WHO, 1979.

18 World Health Organization (WHO). Physical Status: The Use and Interpretation of Antbropometry. Report of a WHO Expert Committee. Geneva: WHO, 1995.

19 Barlow S, Dietz W. Obesity evaluation and treatment: expert committee recommendations. Pediatrics 1998; 102: E29-36.

20 Bailey K, Ferro-Luzzi A. Use of body mass index of adults in assessing individual and community nutritional status. Bulletin of the World Health Organization 1995; 73(5): 673-80.

21 Clinical Guidelines on the Identification'. Evaluation, and Treatment of Overweight and Obesity in Adults - The Evidence Report. National Institutes of Health. Obesity Research 1998; 6(Suppl. 2): 51S-209S.

22 Lean ME, Han TS, Seidell JC. Impairment of health and quality of life in people with large waist circumference. Lancet 1998; 351(9106): 853-6.

23 Jinabhai CC, Taylor M, Sullivan KR. Implications of the prevalence of stunting, overweight and obesity amongst South African primary school children: a possible nutritional 
transition?. European Journal of Clinical Nutrition 2003; 57(2): 358-65.

24 Kain J, Vio F, Albala C. Obesity trends and determinant factors in Latin America. Cadernos de Saúde Pública 2003; 19(Suppl. 1): S77-86.

25 Amigo H. [Obesity in Latin American children: situation, diagnostic criteria and challenges]. Cadernos de Saúde Pública 2003; 19(Suppl. 1): S163-70.

26 Organización de las Naciones Unidas para la Agricultura y la Alimentación (FAO). Perfiles nutricionales por paises: Argentina. Rome: FAO, 2001.
27 Berti P, Leonard W, Berti W. Stunting in an Andean community: prevalence and etiology. American Journal of Human Biology 1998; 10: 229-40.

28 Toselli S, Tarazona-Santos E, Pettener D. Body size, composition, and blood pressure of high-altitude Quechua from the Peruvian Central Andes (Huancavelica, 3,680 m). American Journal of Human Biology 2001; 13(4): 539-47.

29 Siervo M, Grey P, Nyan OA, Prentice AM. Urbanization and obesity in The Gambia: a country in the early stages of the demographic transition. European Journal of Clinical Nutrition 2006; 60(4): 455-63. 